carbo-hydrates, besides those aiready named, are credited with the power of setting up acne of the pustular type. Among these, the commonest are malt liquor and sugar, especially when their ingestion does not folluw out-door exercise. With regard to the rnalt liquors, there is of course another possible explanation of the occurrence of acne. It is the introduction of sulphur and its compounds. There are at least three methods by which sulphur may be introduced in to beer. The hops are dried whilst exposed to the fumes of nascent sujpburous acid; barrels are washed with calrium sulphide to fresben them, and the best beer-making waters, as those of Burton, are rich in the same salc. As we have to deal with two contributory causes of acne pustulosa, seborrboca as a predisposing and scurf as an exciting cause, the question arises, Sball we attack these $(a)$ in their chronological order, $(b)$ together, or $(c)$ in reverse order? The practical rule appears to be to destroy the dandruff first, then see to the seborrhoea. Acne punctata may be removed by means of an ammonia soap which I devised ten years ago for the purpose. Its composition is as follows :- From ten to thirty nunims of liquor ammonia (according to age), one drachm of ether, one ounce of soit soap. To be kept air tight. First foment a small portion of the skin with very hot water, then apply the soap firmly with the ball of the thumb, as if cleaning off varnish from an old oil painting, and very quickly wash away all vestiges of soap. Great care must be taken in using this soap on sensitive parts or on delicate skins, else pretty severe erythema may be set up. Careful dieting, total abstinence from every furm of alcohol, sharp out-door exercise, hot bath, Turkish or electric baths, assist matters. Systematic lung bygiene-i.e., enforced expiration followed bv prolonged pernasal inspiration, brisk towellings, grneral effleurage or skin rolling, seluluus avoidance of excitement, of ices, and of cold beverages, no sea bathing, and the exceptional use of the cold bath, soft woollen clothing, \&e, and the employment of sulphur or arsenic as jnternal remedies according to indications-these are the main outlines of treatment, to be modified by the special exigencies of individual cases.

Berkeley Mansions, Hyde-park, W.

\section{TWO INSTRUCTIVE CLINICAL CASES.}

\section{BY JAMES OLIVER, M.D., F.R S.EDIN.}

CASE 1. Intra-uterine pregnancy; delivery normal._Jane $\mathrm{L}-$ _, aged thirty-seven, and married fifteen years, has had seven children and no miscarriages. The last child was horn in April, 1887. It was suckled for twenty months. The patient became "unwell" for the first time after this confinement, when the infant was twelve montbs old, April, 1888. From April, 1888, until November, 1888, menstruation re curred regularly every month, and was of the usual amount. She was not, however, "unwell" in December, und, thinking it was probable she might be pregnant, she weaned the child. The catamenial discharge appeared again towards the end of January, 1889, and continued for the usual number of days (five). Towards the end of February the was again unwell, and this hæmorrhagic discharge continued during the whole of March and the first fortnight of April, ceasing occasionally for two or even three days. The patient was seen by me on Aug. 1st, and stated that she had not been unwell since the 14th of April. She further stated that she had felt the movements of the child on April 22nd (Easter Monday), and that she had continued to feel the movements until a month ago (some time in July). Eight days before I saw her (about July 24th) the patient heyan to experience pain in the left side and in the hack, coming to the front like "labour pains," and thinking labour had actially begun she sent for her doctor. On Dec. 30th, 1889 , the patient was delivered without the slightest trouble apparently of a full time and living child, a boy. In this case, if we allow 275 days for the duration of pregnancy, the patient must have conceived about March $30 \mathrm{th}$, and yet the catamenial discharge, with the exception of two days, continued during the whole of March and the first fourteen days of April. Besides, quickening was felt on Easter Monday (April 22nd), and, as the woman was already the mother of seven children, this announcement demanded consideration. Taking all the facts and physical signs into consideration, I advised watch- ing ; this was done, and the result was a full-time and living child on Dec. 30th.

CASE 2. Extra uterine pregnancy; delivery by abdominall section.-Clara $\mathrm{M}-$ - aged thirty-seven, and married sixteen years, has had five children and one doubtful miscar. riage. The last child was born twelve years ago. The doubtful miscarriage is supposed to have taken place in April, 1889. The history given in regard to this occurrence is that the patient had not been unwell for eight weeks: thereafter a hæemorrhagic discharge appeared, and continued for seven weeks, ceasing altogether on May 4th. Prior to this amenorrbcal menstruation had recurred regularly every month. About May 26th there was discharge of blood for two days. From May 28th till Christmas the patient was the subject of complete amenorrhœa again. On Christmas Day the catamenial discharge reappeared, and continued for eight weeks. The hrmorrhage ceased about Feb. 7th and thereafter the patient was not unwell again until April 24th, when the discharge appeared, and continued for six days. The patient began to feel movements in October, and these were felt as plainly as they had ever been felt during any of the previous pregnancies, and they were felt continually until two days before Christmas, since which time they have not been felt at all. As the uterus slightly enlarged was felt closely incorporated with a swelling on the left side of the pelvis, and which swelling extended to above. the umbilicus, it was decided to open the abdominal cavity. On May lat the abdominal cavity was opened, and a tull time foetus (dead, but not decomposed) was found in a thick sac located in the left broad limament. The left. Fallopian tube and uterus were both well defined; the left ovary, however, could not be detected. In this case the fotal movements were distinctly felt by the patient in October, and from that time they were ccntinuously felt. until two days before Christmas. The child removed by abdominal section appeared to be a full time child, and it is quite probable, considering the contents of the sac in which the foetus lay, as well as the character of the inner wall of the cavity and the appearance of the placenta, that the child had died soon after Christmas. This being so, what was the probable date of conception? Here, again, if we allow 275 days for the duration of preg. nancy, and calculate back from Dec. 30th, say, which by chance happens to be the day on which Case 1 was normally delivered (see above), conception probably took place about March $30 \mathrm{th}$, and this date corresponds somewhat closely with the amenorrhœa of eight weeks prior to the bæmorrhage which occurred in March and April, and which, it is stated, ceased about May 4 th. The miscarriage, therefore, which it is supposed took place in A pril was most probably not a miscarriage, but an in tercurrent hæmorrhage dependent upon the presence of a developing ovum in the left broad ligament. This patient had never experienced any pain like labour, although she had complained more or less of pain in the lower abdomen ever since May.

Gordon-square, W.C.

\section{OClinital allotes:}

\section{MEDICAL, SURGICAL, OBSTETRICAL, AND} THERAPEUTICAL.

\section{CLCBBING OF FINGERS AND TOES.}

By Anger Money, M.D., F.R.C.P.

Is venous congestion the chief cause of clubbing of the fingers, toes, nose, ear-lobules, lower end of the spinal cord, and the most distal extremities of the circulation? Textbooks are silent on the relationship between clubbing and cyanosie in congenital heart disease. An average statement is: "Clubbing of the fingers and toes is very characteristic " of morbus coruleus.

$\Lambda$ female child, aged ten months, died with acute paralytic dilatation of a congenitally diseased heart. It was exceedingly blue at all times, and had been so from one day after birth. Screaming notably increased the blueness, perhaps partly because screaming and kicking increased the pnverty of the oxyhamoglobin. But to the point at issue. No trace of clubbing, and cyanosis of ten montbs' duration. Necropsy revealed entire absence of the ventricular septum. 